\title{
Effects of complete and incomplete reward reduction on a subsequent response'
}

\author{
ROBERT J. BARRETT, CHARLES S. PEYSER AND JAMES H. MCHOSE \\ SOUTHERN ILLINOIS UNIVERSITY
}

\begin{abstract}
Four groups of 6 rats received 48 acquisition and 36 postshift trials in an L-shaped double alley. Groups were differentiated by the amount of reward received in the first goal box $\left(G_{1}\right)$ on each acquisition trial. In the postshift phase, three groups received test trials on which reward in $G_{1}$ was reduced by varying amounts. Analyses of second alley speeds indicated facilitative effects of complete removal of reward in $\mathrm{G}_{1}$ but not of incomplete reward reduction.
\end{abstract}

\section{Problem}

Several studies have shown that rats run faster in the second alley $\left(\mathrm{A}_{2}\right)$ of a double alley apparatus following nonreinforcement as compared with reward in the first goal box $\left(\mathrm{G}_{1}\right)$.Wagner's (1959) study, in which an experimental group received both rewarded and nonrewarded trials in $\mathrm{G}_{1}$ and a control group never received reward in $G_{1}$, showed that $A_{2}$ speeds of the experimental group following nonreward were greater than $\mathrm{A}_{2}$ speeds of the control group. These data support the contention that increases in $\mathrm{A}_{2}$ speeds result from omission of an expected reward.

Recent evidence (McHose \& Ludvigson, in press) indicates that incomplete reduction in $\mathrm{G}_{1}$ reinforcement, to some nonzero value, does not facilitate $\mathrm{A}_{2}$ response speeds. The previous observation (Bower, 1962) that $\mathrm{A}_{2}$ speeds increase as reduction value (training minus obtained magnitude) increases presumably reflects the effect of the absolute amount obtained, which was confounded with reduction value. In this connection, the McHose \& Ludvigson data do indicate that $\mathrm{A}_{2}$ speeds vary inversely with the absolute amount received in $\mathrm{G}_{1}$. The generality of the McHose \& Ludvigson data are limited by the fact that only one amount of incomplete reduction from one training magnitude was employed. The present study involved several initial training magnitudes and varying amounts of reward reduction. This study also provides data on the effects of complete removal from various training magnitudes.

\section{Method}

Twenty-four hooded and albino rats received 48 acquisition and 36 postshift trials in an L-shaped double alley apparatus previously described (McHose \& Ludvigson, in press). The apparatus consisted of two runways in series each comprised of a start, alley and goal section with the first goal box $\left(G_{1}\right)$ serving as the start box for the second alley $\left(\mathrm{A}_{2}\right)$. Photocellclock circuitry provided traversal time measures in $\mathrm{A}_{2}$.
Ten days prior to the first training day, Ss were placed on a 23-hr. food deprivation cycle maintained throughout the experiment. On the two days immediately preceding the first training day, Ss received approximately $1 \mathrm{gm}$ of $45-\mathrm{mg}$ Noyes pellets, identical with the subsequent reinforcement pellet, prior to their daily ration.

Four groups of six Ss each were randomly constituted and designated according to the number of pellets received in $G_{1}$ on each acquisition trial: Groups 12, 8, 4 , and 0 . During the postshift period each group received their training magnitude in $\mathrm{G}_{1}$ on $75 \%$ of the trials, the remaining trials being equally distributed among a variety of "test trial" conditions. On test trials each group received, over the postshift period, each relevant multiple of a 4 pellet reduction in $\mathrm{G}_{1}$. Thus Group 12 received, on various postshift trials, $12,8,4$, or 0 pellets (conditions 12-12, 12-8, 12-4, and 12-0 respectively); Group 8 received 8,4 , or 0 pellets etc. All Ss always received 2 pellets in the second goal box.

Reciprocal traversal time for an intermediate 1-ft section of $\mathrm{A}_{2}$ was recorded on each trial.

\section{Results}

In Fig. 1 the combined mean running speeds over trials 49-60 and 73-84 for the various conditions of $\mathrm{G}_{1}$ reward decrement are plotted relative to those for the control group trained at, and obtaining, the test value (e. g., the $12-0,8-0$, and $4-0$ speeds relative to

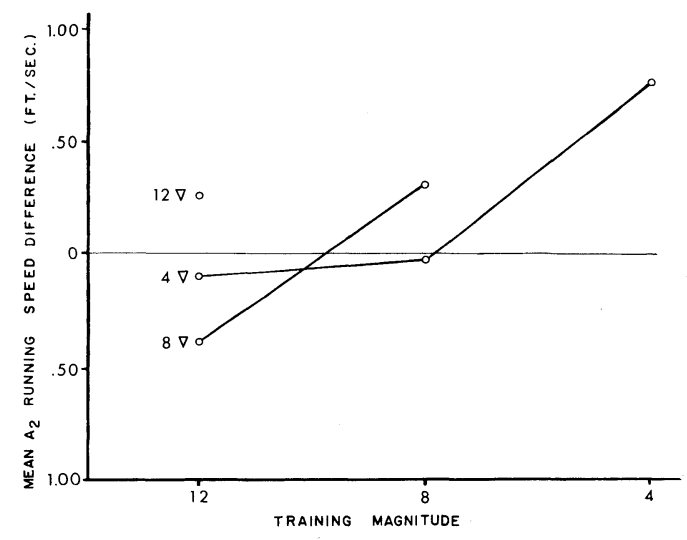

Fig. 1. Mean $A_{2}$ running speed deviations, experimental minus control for each of the various reductions as a function of training magnitude. 
those for the 0-0 group; the $12-4$ and $8-4$ relative to the 4-4, etco). Thus ordinate deviations from 0 are effects of $G_{1}$ reward reduction per se on $A_{2}$ speeds. As may be seen, only complete reward reduction appeared to facilitate $\mathrm{A}_{2}$ speeds. Variance analysis of the complete reduction trials $(12-0,8-0,4-0,0-0)$ yielded a significant groups effect, $F(3,16)=33.46$, $\mathrm{p}<.01$. Using the Tukey (a) technique (Winer, 1962) $(\propto=.01)$, each experimental group differed significantly from the (0-0) control condition. Group 4-0 was also significantly faster than Groups 12-0 and 8-0. No other contrasts were significant.

Two notable results are not depicted in Fig. 1. First, within each group, $\mathrm{A}_{2}$ speeds increased in proportion to the amount of reward reduction. Only 3 of the 36 different individual organism comparisons did not show this ordinal relationship. Variance analysis of the 12-12, 8-8,4-4, and 0-0 data yielded a significant groups effect, $F(3,16)=33.41, p<.01$. Speeds varied inversely with the amount of reward received in $G_{1}$, with the exception of those for Group 0-0, which were slightly below those for Group 4-4.

\section{Discussion}

The present data confirm and extend the results of McHose \& Ludvigson (in press) in that no facilitative effects of incomplete reward reductions per se were observed. Moreover, both studies yield an inverse relationship between absolute amount obtained in $\mathrm{G}_{1}$ and $\mathrm{A}_{2}$ speeds. The latter variable accounts for the observation in these and Bower's (1962) data that $\mathrm{A}_{2}$ speeds increase when $G_{1}$ reward is decreased. The present data serve to emphasize the need for control of obtained (absolute) magnitude in assessing the effects of the (training minus obtained) reduction variable. In each instance complete removal of reward did facilitate $\mathrm{A}_{2}$ performance, a finding in accord with previous data (Wagner, 1959). The only explicit theory applicable to partial as well as complete reduction in the reward, Bower's (1962) $r_{g}$ perseveration hypothesis, does not adequately describe the present results, since it predicts facilitative effects of both incomplete and complete reward reductions.

According to Amsel's (1958) frustration theory, the facilitative effects of nonreinforcement should vary directly with $G_{1}$ training magnitude, since the amount of frustration-drive increment is said to vary with $r_{g}$ level and $\mathrm{r}_{\mathrm{g}}$ in turn is directly related to training magnitude in the present data. It should be noted, however, that Peckham \& Amsel (1964) report faster $\mathrm{A}_{2}$ speeds following nonreward in an 8 as compared with a 2-pellet $\mathrm{A}_{1}$ discriminandum.

\section{References}

Amsel, A. The role of frustrative nonreward in noncontinuous reward situations. Psychol. Bull., 1958, 55, 102-119.

Bower, G. The influence of graded reductions in reward and prior frustration events upon the magnitude of the frustration effect J. comp. physiol. Psychol., 1962, 55, 582-587.

McHose, J., \& Ludvigson. H. The role of reward magnitude and incomplete reduction of reward magnitude in the frustration effect. J. exp. Psychol., in press

Peckham, R., \& Amsel, A. Magnitude of reward and the frustration effect in a within-subjects design. Psychon. Sci., 1964, 1, 285-286.

Wagner, A. The role of reinforcement and nonreinforcement in an "'apparent frustration effect." J. exp. Psychol., 1959, 57, $130-136$

Winer, B. Statistical principles in experimental design. New York: McGraw-Hill, 1962.

\section{Notes}

1. Supported in part by grant $\mathrm{MH} 10340$ from the United States Public Health Service

2. Conducted during tenure as NDEA predoctoral Fellow 